\title{
NBSIR 74.603
}

\section{A Standard Procedure for Setting of Photoelectric Controls Prior to Installation on Lighted Obstructions}

\section{Nimeroff}

Heat Division, Optical Radiation Section Institute for Basic Standards National Bureau of Standards

Washington, D. C. 20234

October, 1974

Final Report

\section{Prepared for}

Federal Aviation Administration

Washington, D. C. 20590 
NBSIR 74-603

\section{A STANDARD PROCEDURE FOR SETTING \\ OF PHOTOELECTRIC CONTROLS PRIOR \\ TO INSTALLATION ON LIGHTED OBSTRUCTIONS}

I. Nimeroff

Heat Division, Optical Radiation Section

Institute for Basic Standards

National Bureau of Standards

Washington, D. C. 20234

October, 1974

Final Report

Prepared for

Federal Aviation Administration

Washington, D. C. 20590

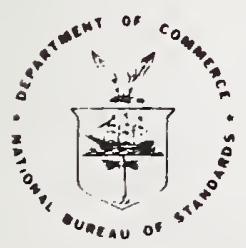

U. S. DEPARTMENT OF COMMERCE, Frederick B. Dent, Secretary

NATIONAL BUREAU OF STANDARDS, Richard $w$. Roberts. Director 
The Federal Aviation Administration of the U. S. Department of Transportation, requested the National Bureau of Standards to prepare a standard procedure by which photoelectric controls could turn on and off, or turn on and control the intensity of obstruction lights in accordance with the specifications of FAA Advisory Circular AC 70/74601C. The work included a study of the spectral properties of available materials to simulate twilight conditions that prevail when the photoelectric controls operate.

The opinions, findings, and conclusions in this report are those of the author and are not those of the Federal Aviation Administration. Certain commercially available equipment, instruments, or materials are identified in this report to specify adequately the procedures used. In no case should such identification be inferred as either recommendation or nonendorsement by the National Bureau of Standards, nor does the identification imply that the materials are necessarily the best available for the purpose. 


\section{Contents}

Page

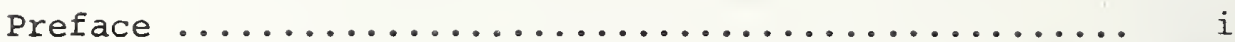

Abstract ................................. ii

1. Introduction $\ldots \ldots \ldots \ldots \ldots \ldots \ldots \ldots \ldots \ldots \ldots \ldots \ldots \ldots \ldots \ldots \ldots$

2. Requirements of the Light Control Device ........... I

3. Calibrating Device Requirements ................ 2

4. Design of Calibrating Device ................. 2

5. Selection of Distances ......................... 5

6. Recommended Calibrating Procedure .............. 10

6.1 Photometric Equipment ................. 10

6.2 Setting Procedure $\ldots \ldots \ldots \ldots \ldots \ldots \ldots \ldots \ldots \ldots$

7. Discussion $\ldots \ldots \ldots \ldots \ldots \ldots \ldots \ldots \ldots \ldots \ldots \ldots \ldots \ldots \ldots \ldots$ 
Abstract

A calibration device was designed and a procedure was developed by which photoelectric controls of obstruction lights could operate in accordance with specification requirements of $F A A$ Advisory Circular AC 70/74601C. The device, consisting of a source and a diffuser-filter, was designed primarily to provide the photocell of the control with diffuse illumination of proper spectral distribution to approximate normal twilight conditions. Illumination at the photocell is varied by changing the distance between the source and the diffuser-filter. Because there may be wide variation from normal twilight conditions, causes of such variation and their possible effects are also discussed. 
A Standard Procedure for Setting of Photoelectric Controls Prior to Installation on Lighted Obstructions

\section{Introduction}

In a letter dated March 29, 1974, the Federal Aviation Administration requested the National Bureau of Standards to prepare, under Inter-Agency Agreement, DOT-FA72WAI-299, a standard procedure by which photoelectric controls could turn on and off, or turn on and control the intensity of obstruction lights in accordance with the specification requirements of FAA Advisory Circular AC 70/74601C. This report is in response to that request.

\section{Requirements of the Light Control Device}

FAA Standard on Obstruction Marking and Lighting, AC 70/74601C, requires that a light-sensitive control device be installed so that it faces the north sky. The device is used to control the on and off condition of aviation red obstruction lighting and flashing red hazard beacons, and to control the daytime, twilight, and nighttime conditions of light intensity emitted by high-intensity flashing white obstruction lights.

The light control is required to operate the red lights when the illuminance on the photodetecting surface is 30 footcandles or less and to turn off the lights when the illuminance is 60 footcandles or more.

The control is required to change the setting of the highintensity flashing white obstruction lights when the illuminance level on the photodetecting surface of the device meets the following conditions:

1. The night setting shall be switched to the twilight setting, and the twilight setting to the night setting, when the illumination is in the range 2 to 5 footcandles inclusive.

2. The twilight setting shall be switched to the day setting, and the day setting to the twilight setting, when the illumination is in the range 30 to 60 footcandles, inclusive. 


\section{Calibrating Device Requirements}

A calibrating device is required that will produce at the entrance window of the control device a diffuse illumination that simulates in spectral distribution and magnitude the ambient north sky characteristics at twilight conditions. Diffuse illumination at the photoelectric control may be obtained by placing the entrance window of the control against one surface of a diffuser and illuminating the other surface, as shown in Figure 1 .

The proper spectral distribution, estimated to have a correlated color temperature of about $5000 \mathrm{~K}$, can be achieved by mounting an optical filter onto the diffuser, between the source and the diffuser, as in Figure 1. An alternate diffuser-filter may be a simple, properly colored diffusing material as is shown in Figure 2 .

The magnitude of the illuminance $E_{\text {on }}$ on the photoelectric control is determined by the illuminance $\mathrm{E}$ on the diffuser-filter and its luminous transmittance $\tau$, thus

$$
E_{p}=E \tau
$$

The illuminance on the diffuser-filter depends on the intensity I of the source and the distance $d$ between the filter and source. The illuminance from the source may be varied by changing the distance because

$$
E=I / d^{2}
$$

(The illuminance should not be varied by changing the voltage applied to the source to change its intensity, as this procedure also changes the spectral distribution of the emitted flux.) By combining equations (1) and (2) the illuminance on the photosensitive surface of the photoelectric control is found as

$$
E_{p}=\tau I / d^{2}
$$

\section{Design of a Calibrating Device}

To alter the spectral distribution of the light emitted by an incandescent tungsten-filament lamp from a color temperature of $2856 \mathrm{~K}$ to approximately $5000 \mathrm{~K}$ requires an optical filter that has high transmittance in the blue (short wave) end of the visible spectrum and low transmittance in the red (long wave) end. The ideal spectral transmittance of such a filter is shown 

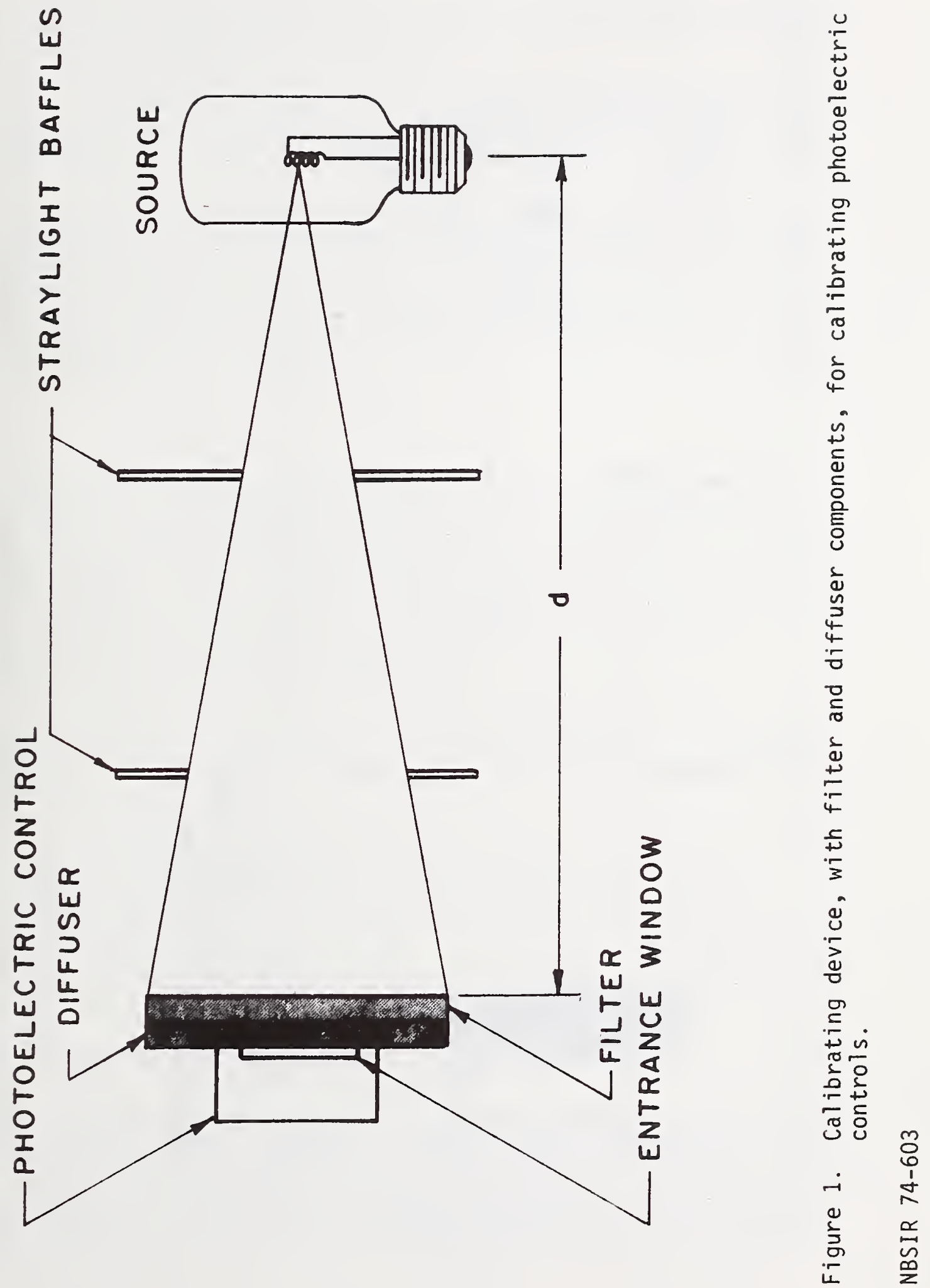

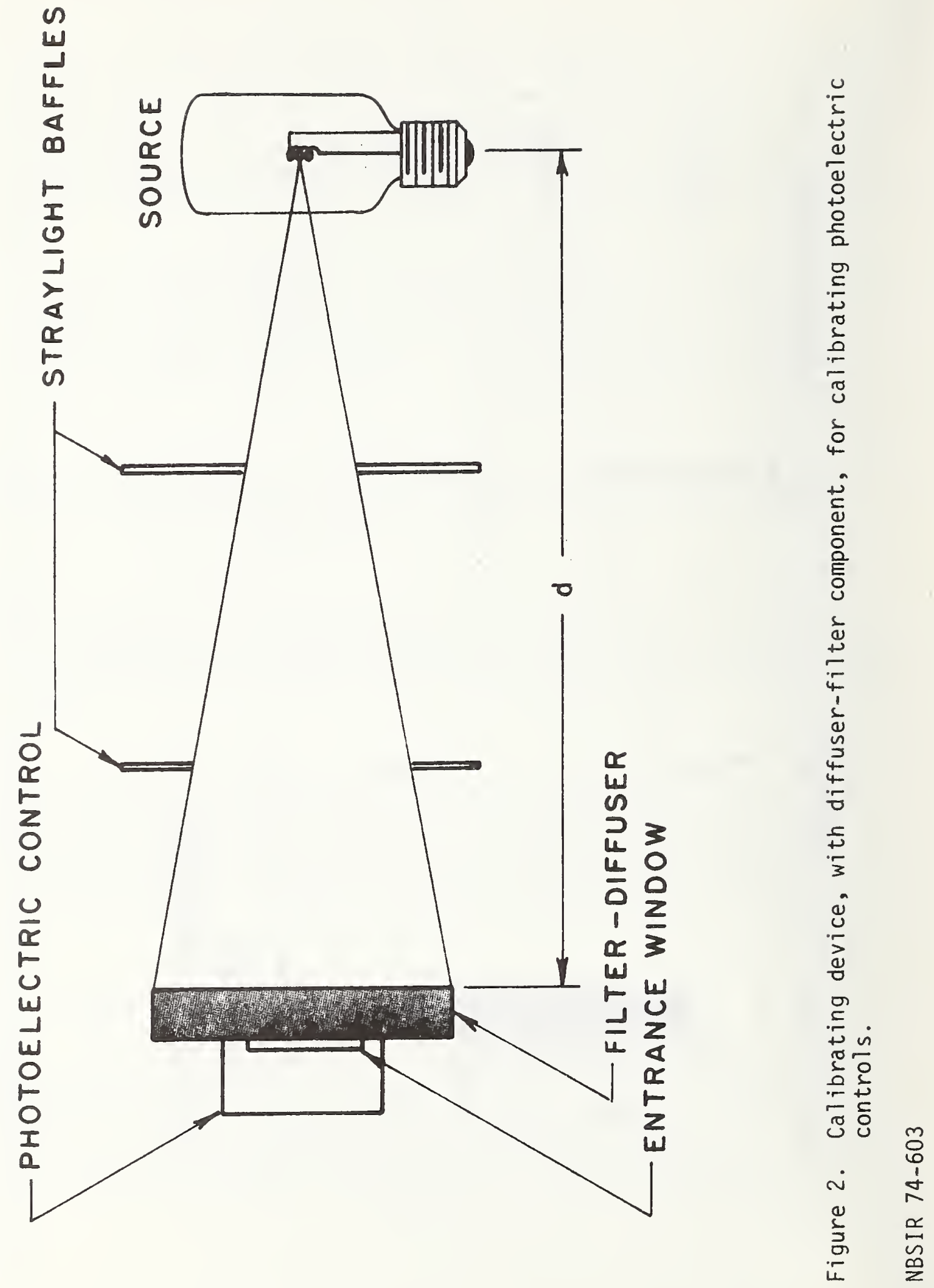
in Figure 3. This filter has the spectral distribution needed to simulate color temperature $4800 \mathrm{~K}$ when used with a source operating at a color temperature of $2856 \mathrm{~K}$.

Two materials were found that could alter the spectral distribution of a lamp operating at color temperature $2856 \mathrm{~K}$ to approximate a source of color temperature $5000 \mathrm{~K}$.

Optical filtering materials are made in nominal stock thickness $d$ with corresponding spectral transmittance $\tau_{0}$ for a specific colorant concentration. The spectral transmittance can be varied to transmittance $\tau$ by varying the thickness to a relative thickness $d_{1}=a d_{0}^{\prime}$, where $a$ is the fraction $d_{1} / d_{0}$ of stock thickness. The fraction of stock thickness and transmittance are related by the equation,

$$
\tau_{1}=\left(\tau_{0}\right)^{a}\left(k^{2}\right)^{1-a}
$$

where $\mathrm{k}$ is unity minus specular reflectance. By varying the thickness of the materials in order to vary the spectral transmittance, then computing the chromaticity coordinates at several thicknesses and from these data evaluating the correlated color temperature, a plot of color temperature against relative thickness can be drawn. See Figure 4. Such a plot can be used as an aid in choosing the proper thickness of material to obtain the desired color temperature change.

From these curves it can be seen that Corning glass, type 5900, of $0.83 \mathrm{~d}\left(\mathrm{~d}_{\mathrm{o}}=\right.$ nominal stock thickness) will alter color temperature $2856 \mathrm{~K}$ to $5000 \mathrm{~K}$, as will Rohm and Haas Plexiglass, type 2329 , of $0.49 \mathrm{~d}_{0}$.

The type 5900 glass filter at a relative thickness of $2 / 3$ d yields a color temperature of approximately $4630 \mathrm{~K}$ with luminous transmittance of 0.36. See Figure 5. The type 2329 plexiglass filter at a relative thickness of $1 / 2 \mathrm{~d}$ yields a color temperature of about $5130 \mathrm{~K}$ with luminous transmittance of 0.29. The spectral transmittance of these filters is shown in Figure 6 for two thicknesses.

\section{Selection of Distances}

Since the illuminance requirements for turning on or increasing the light output, and turning off or decreasing the light output of obstruction lighting are specified, there remains only the problem of setting the proper distance between the calibrating source and the calibrating diffuser-filter to obtain the required illuminance. To determine the distances to obtain 


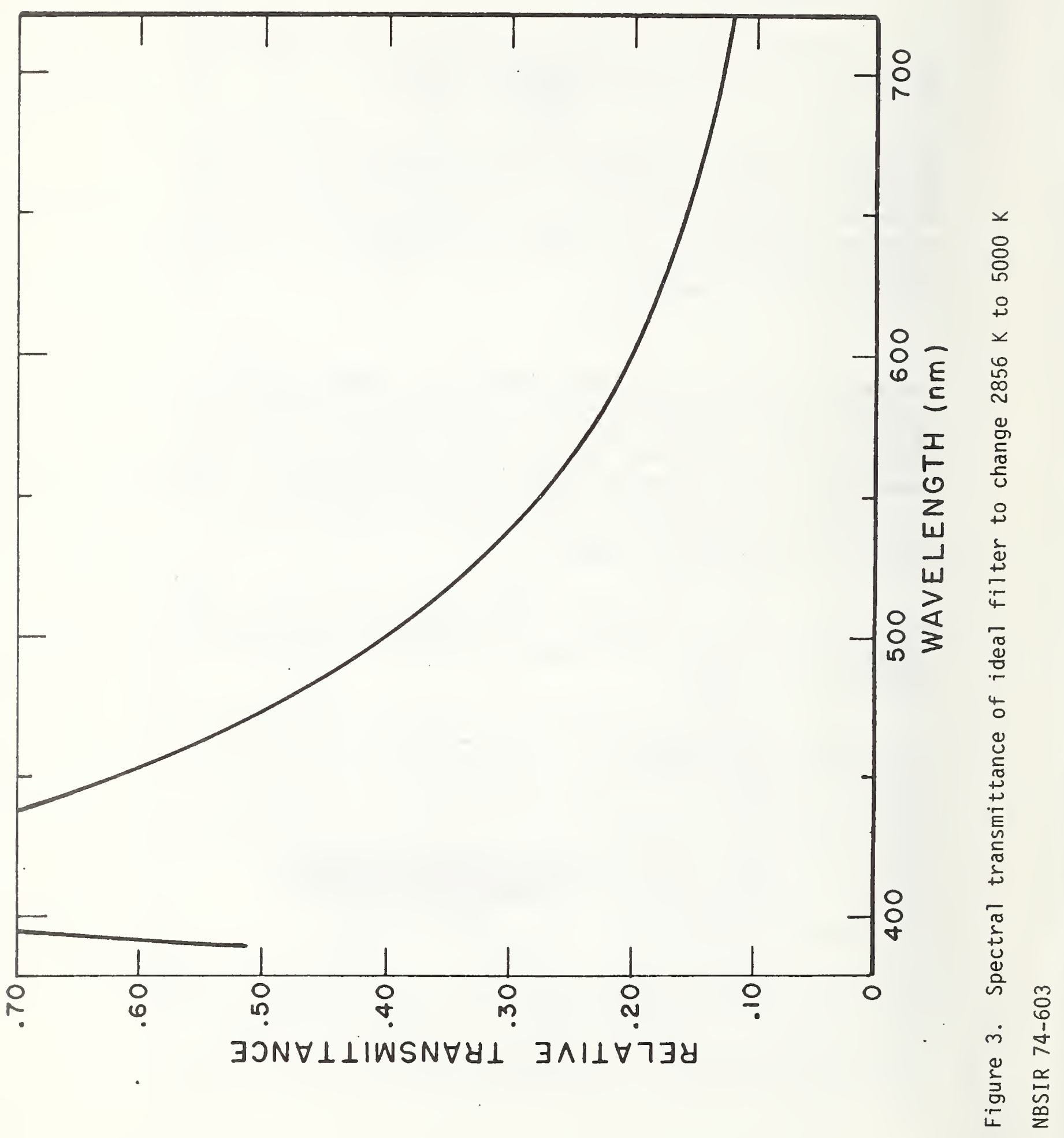




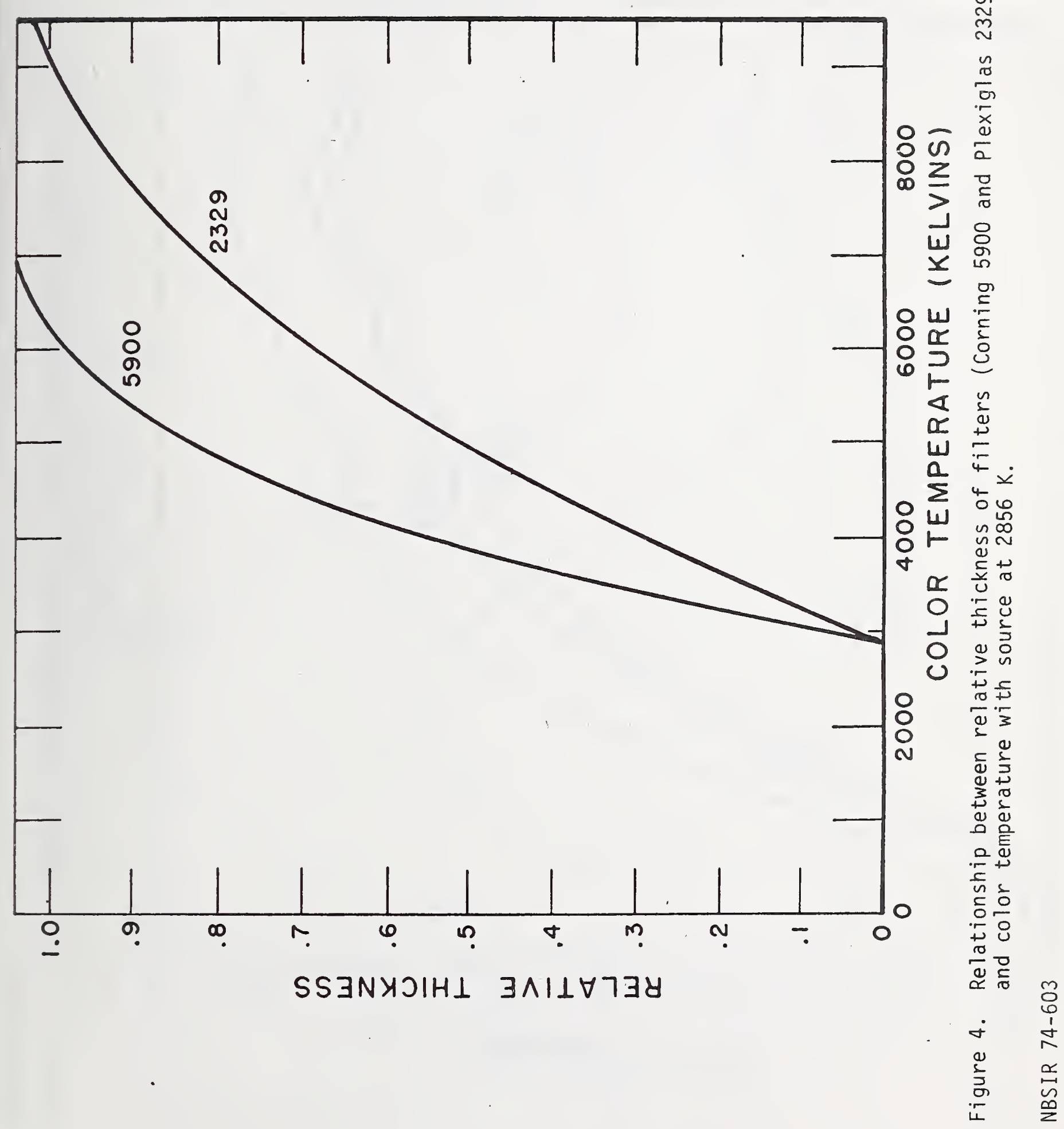




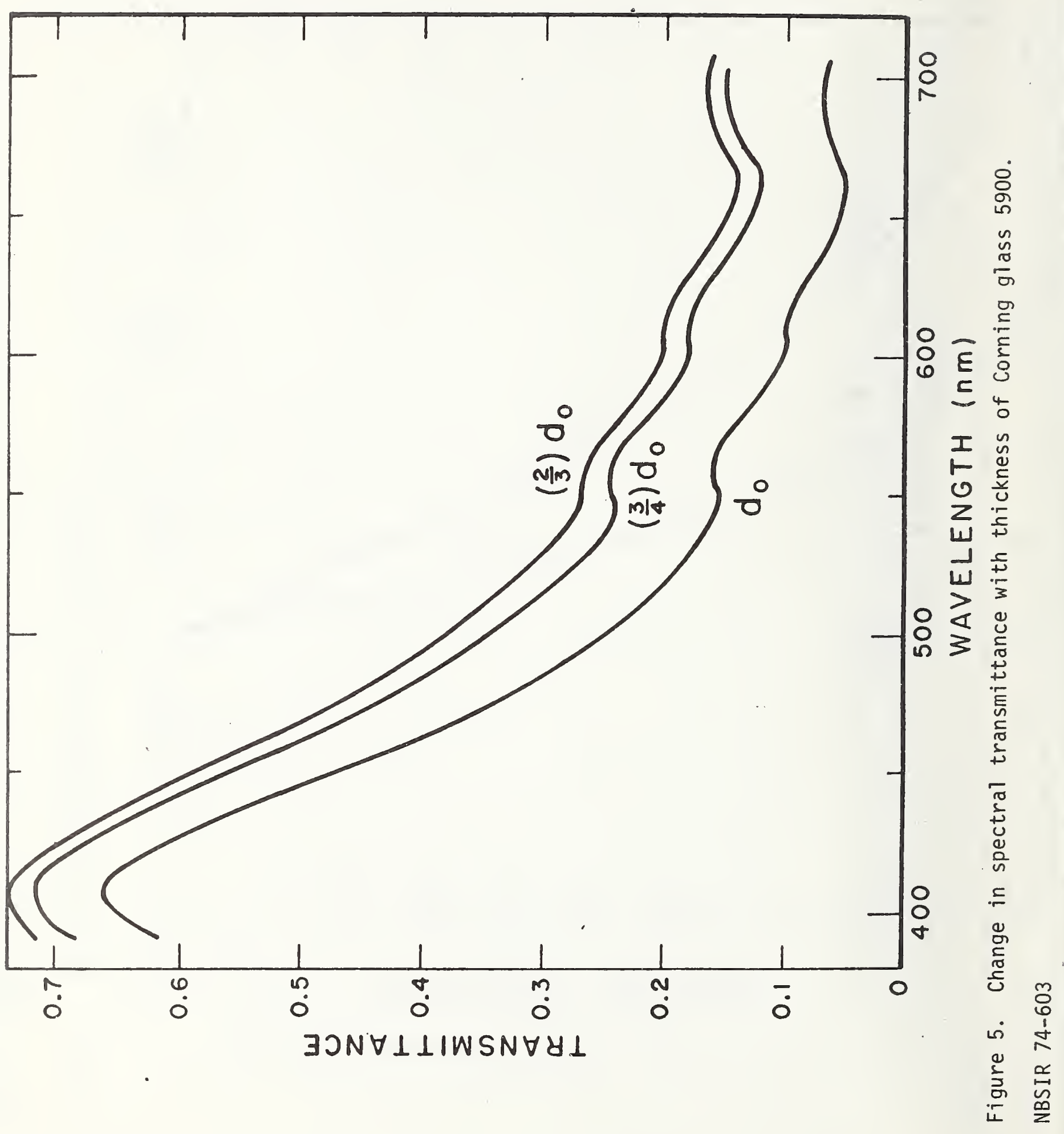




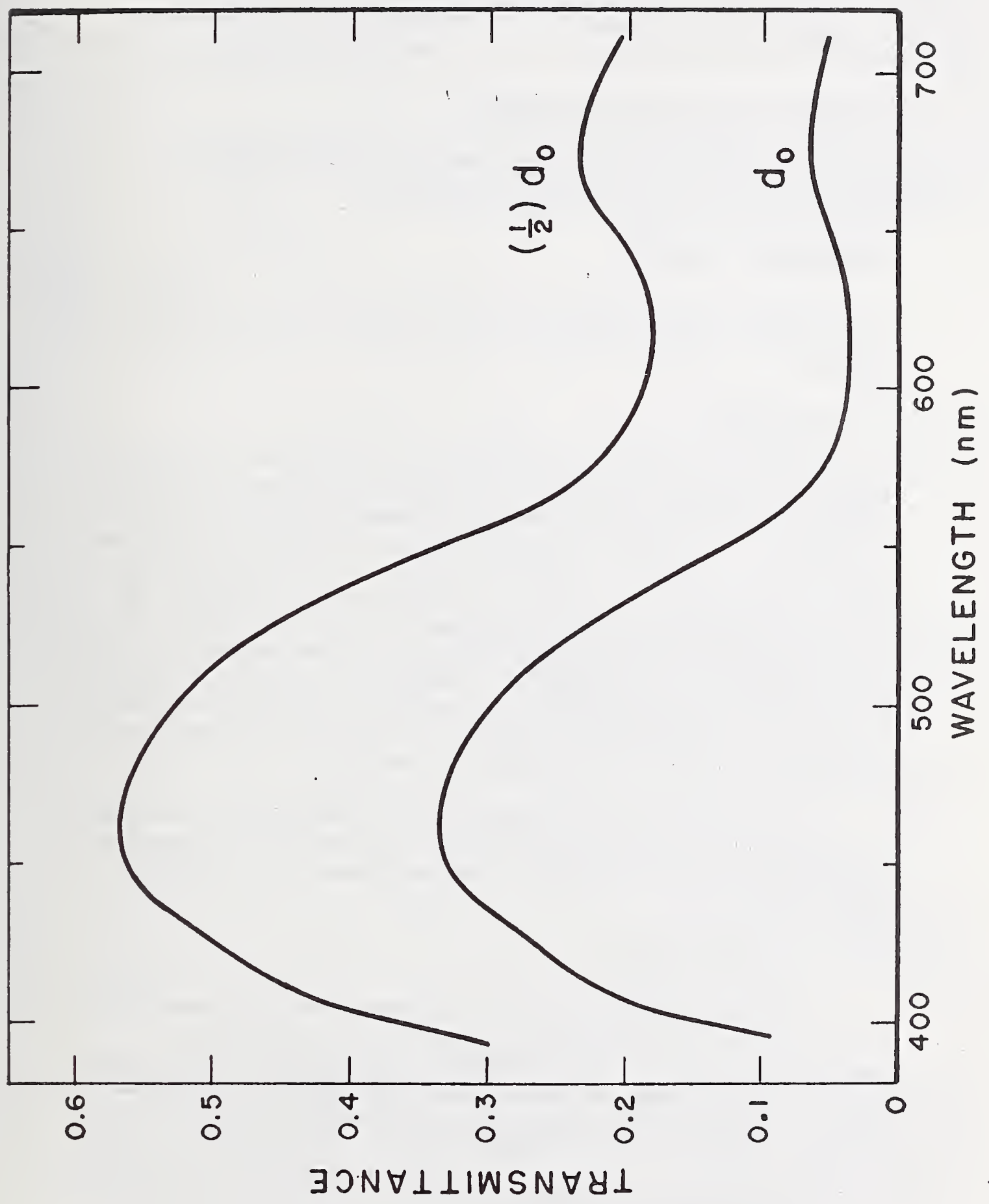


the required illuminance on the photoelectric control, equation

(3) should be solved. Thus, as an example, with a 500-watt projection lamp of 700 candelas and a diffuser-filter combination of transmittance 0.30 , a distance of 0.57 meters will yield an illumination of 60 footcandles at the photoelectric control.

\section{Recomended Calibrating Procedure}

The following procedure is recommended for presetting photoelectric controls for lighted obstructions.

\subsection{Photometric Equipment}

The photometric equipment shall consist of a source, source power supply, source mount, optical bench, baffles, filter and diffuser (or diffuser-filter combination) and mount.

\section{1 .1 Source}

The source shall be a 500-watt, or larger, incandescent filament projection lamp of known luminous intensity when operated at the proper voltage to obtain a color temperature of $2856 \mathrm{~K}$. It shall be positioned in its mount so that the axis of its filament is perpendicular to the optical axis. The optical axis is an axis that intersects the center of the lamp filament axis and the center of the diffuser-filter. In a lamp that has a single $\mathrm{C} 8$ or $\mathrm{CC} 8$ filament its axis passes through the gross coils, while in a lamp that has a $\mathrm{Cl} 3$ or $\mathrm{CCl} 3$ filament configuration its axis passes through the plane of the configuration in a plane parallel to the long dimension of the individual filaments.

The plane of the diffuser-filter combination shall be perpendicular to the optical axis. Baffles shall be placed between the source and the filter diffuser to eliminate stray light.

\section{1 .2 Diffuser-Filter}

The diffuser-filter shall be either a single-component plate or a multiple-component plate that diffuses and selectively absorbs the light from the source to alter the spectral distribution from a color temperature of $2856 \mathrm{~K}$ to $5000 \mathrm{~K} \pm 500 \mathrm{~K}$. The luminous transmittance of the diffuser-filter shall be known.

\subsubsection{Arrangement of Components}

The components of the calibrating devices shall be arranged as shown in either Figures 1 or 2 of this report. 
Care shall be taken to mount the source, the diffuser-filter, and the photoelectric control of the control device so that they are properly aligned.

\subsection{Setting Procedure}

(1) From the known intensity of the source I and the known luminous transmittance of the diffuser-filter $t$, determine the distances between source and diffuser-filter to yield the specified illumination $E_{\text {on }}$ on photoelectric control devices. Use the following equation to compute these distances $d$,

$$
\begin{aligned}
& E_{p}=I \tau / d^{2} \\
& \text { or } d=\left(I \tau / E_{p}\right)^{1 / 2}
\end{aligned}
$$

(2) When the source is operating and placed at each of the computed distances, set the photoelectric control devices so that it turns on or increases, or turns off or decreases the light output of the obstruction lights as prescribed in FAA Standard AC 70/7460-1C.

\section{Discussion}

The procedure described in this report primarily considers the approximation of the spectral characteristics of the light incident on the photoelectric control during calibration to that during operation. Employment of a diffusing component in the calibrating system is an attempt to approximate the typical illuminating conditions of use. Because in use the photosensitive surface of the photoelectric control is directed at the north sky, a diffuse luminance standard is a better approximation to typical conditions than a bare lamp standard of horizontal intensity. The output of these detectors is a function of the field of view of the receiver when the detector views the sky, or a diffuse luminance standard, but, it is essentially independent of the field of view when illuminated by a bare lamp. Thus two detectors calibrated with a bare lamp might have quite different outputs when illuminated by the sky or a diffuse standard.

It must, however, be noted that the ambient illumination conditions under which the controls do operate may vary considerably from the predominating illuminating conditions. One of the conditions that may cause too high an illumination on the photoelectric control is snow-covered ground. In this condition the control would set the high intensity white lights for nighttime later than required and would set the lights for daytime too early in the morning. The red lights would be turned on later, and off earlier, when the ground is snow covered. 
This effect would also prevail in certain conditions of fog and haze. In other conditions, that is when the fog and haze are dense, skylight may be attenuated sufficiently to cause the control to set for nighttime earlier and for daytime later than required.

There are, in addition to the causes discussed above, others that will affect the illumination on the photoelectric control device. Some of these are:

1. Location of photocell on tower

2. Height of tower

3. Elevation of site of tower

4. Variation of sky brightness

5. Presence of low clouds

6. Duration of twilight which determines period of uncertainty.

Because of the complex nature of these sources of variation of ambient lighting conditions and the unpredictability of their occurence, either singly or in combination, the best that can be done at the outset is to set the calibration according to the present requirements of AC 70/74601C. Then, after some trial period, the calibration system is evaluated on the basis of its effectiveness at a particular location. If it is found to be adequate no further work will be needed. If, however, it is found wanting for certain locations where one or more sources of variation predominate, adjustments in setting can be made to accomodate the ambient illuminating conditions.

After this report was drafted, we received a copy of the October, 1974, issue of the Journal of the Illuminating Engineering Society which contained, on pages 69-71, the IES Guide for Calibration of Photoelectric Control Devices. The specific procedures recommended in this report are consistent with the general procedures given in the IES Guide for Calibration of Photoelectric Control Devices. 
NBS.IIUA IREV. 7.73)

\begin{tabular}{|c|c|c|c|}
\hline $\begin{array}{l}\text { U.S. DEPT. OF COMM. } \\
\text { BIBLIOGRAPHIC DATA } \\
\text { SHEET }\end{array}$ & $\begin{array}{l}\text { 1. PURLICATION OR REIPORT NO. } \\
\text { NBSIR } 74-603\end{array}$ & $\begin{array}{l}\text { 2. Gov't Accession } \\
\text { No. }\end{array}$ & 3. Recipient's Accession No. \\
\hline \multirow{2}{*}{\multicolumn{3}{|c|}{$\begin{array}{l}\text { 4. TITLE AND SUBTITLE } \\
\text { A Standard Procedure for Setting of Photoelectrïc Controls } \\
\text { Prior to Installation on Lighted Obstructions }\end{array}$}} & $\begin{array}{l}\text { 5. Publication Date } \\
\text { October } 1974\end{array}$ \\
\hline & & & 6. Performing Organization Code \\
\hline \multicolumn{3}{|c|}{$\begin{array}{l}\text { 7. AUTHOR(S) } \\
\text { I. Nimeroff }\end{array}$} & $\begin{array}{l}\text { 8. Herforming Otgan. Keport No. } \\
\text { NBSIR } 74-603\end{array}$ \\
\hline \multirow{2}{*}{\multicolumn{3}{|c|}{$\begin{array}{l}\text { 9. PERFORMING ORGANIZATION NAME AND ADDRESS } \\
\text { NATIONAL BUREAU OF STANDARDS } \\
\text { DEPARTMENT OF COMMERCE } \\
\text { WASHINGTON, O.C. } 20234\end{array}$}} & $\begin{array}{l}\text { 10. Project/Task/Work Unit No } \\
2211500\end{array}$ \\
\hline & & & $\begin{array}{l}\text { 11. Contract/Grant No. } \\
\text { Inter-Agency Agreement } \\
\text { DOT-EAT2WAI-299 }\end{array}$ \\
\hline \multirow{2}{*}{\multicolumn{3}{|c|}{$\begin{array}{l}\text { 12. Sponsoring Organization Name and Complere Address (Stroet, Ciry. } \\
\text { Federal Aviation Administration } \\
\text { Washington, D. C. } 20590\end{array}$}} & $\begin{array}{l}\text { 13. Type of Report \& Period } \\
\text { Covered } \\
\text { Final, Oct. } 1974 \\
\end{array}$ \\
\hline & & & 14. Sponsoring Agency Code \\
\hline
\end{tabular}

15. SUPPLFMENTARY NOTES

16. ABSTR ACT (A 200-word or lesa fectual summary of most sienilicant intormation. Il document includes a signilicant bibliodraphy of literature survey, mention it here.)

A calibration device was designed and a procedure was developed by which photoelectric controls of obstruction lights could operate in accordance with specification requirements of FAA Advisory Circular AC 70/7460-1C. The device, consisting of a source and a diffuser filter, was designed primarily to provide the photocell of the control with diffuse illumination of proper spectral distribution to approximate normal twilight conditions. Illumination at the photocell is varied by changing the distance between the source and the diffuser filter. Because there may be wide variation from normal twilight conditions, causes of such variation and their possible effects are also discussed.

17. KEY VORDS (six to twelve ontries; alphabelical order; capitalize only the tirst letter of the tirst key word unless a proper name; separaled by semicolone)

Obstruction lights; photoelectric calibration device; photoelectric controls; illumination controls; television tower obstruction lighting; tower obstruction lighting

18. AVAILABILITY [Unlimited

[Xfor Official Distribution. Do Not Release to NTIS

Order From Sup. of Doc., U.S. Government Printing Office Washington, D.C. 20.402, SD (at. No. (.13

Order From National Technical Information S'ervicé (NTIS) Springfield, Virginia 22151

\begin{tabular}{|c|c|}
\hline $\begin{array}{l}\text { 19. SECURITY CI.ASS } \\
\text { (THIS REPURT) } \\
\text { (INCL.ASSIFIFD }\end{array}$ & $\begin{array}{c}\text { 21. NO. OF PAGES } \\
17\end{array}$ \\
\hline $\begin{array}{l}\text { 20. TE( URITY (I.ASS } \\
\text { (TIUS PAGE) } \\
\text { UNCLASSIFUED }\end{array}$ & 22. Price \\
\hline
\end{tabular}


